\title{
PAROXYSMAL VENTRICULAR TACHYCARDIA
}

\author{
A CLINICAL CLASSIFICATION
}

\author{
BY \\ ROGER FROMENT, LÉON GALLAVARDIN, AND POL CAHEN \\ From the Medical School and the Edouard-Herriot Hospital, University of Lyon, France
}

Received October 2, 1952

The Lyonese school has been interested since 1920 in the subject of paroxysmal ventricular tachycardia. The excellent article by Armbrust and Levine (1950), based upon the study of one hundred cases, has encouraged us to attempt again to classify the different forms of this abnormal rhythm.

Although this disorder was identified in 1909 by Thomas Lewis it was Louis Gallavardin who, as early as 1920 , described and emphasized the terminal prefibrillatory ventricular tachycardia, the extreme gravity of which he underlined by this very title. At the same time, he described the first clinical sign of ventricular paroxysms, namely the presence of a slow dissociated jugular pulse, a clinical proof of the independent auricular rhythm registered electrocardiographically. Soon after, in 1922, these severe forms were compared by him with a milder form of ventricular paroxysms: ventricular extrasystoles with paroxysms of tachycardia. About the same time others confirmed and extended these original descriptions. We may mention the studies of Robinson and Herrmann (1921) stressing the frequency of myocardial infarction as the precipitating cause of these ventricular paroxysms, and also the work of Dieuaide and Davidson (1921), of Gallemaerts (1923), and of Wolferth and McMillan (1923), which emphasized the remarkable therapeutic action of quinidine during such attacks. By this time, severe forms of ventricular tachycardia were well recognized and observations were reported from many quarters, but the milder forms still received little notice (Parkinson and Papp, 1947).

The study of paroxysmal ventricular tachycardia presented by Froment in 1932, and made under Gallavardin's direction constituted a step towards classification. In this work, based on personal observations and on an exhaustive survey of published cases up to that date, we distinguished the following varieties.

(1) Severe and terminal forms of ventricular tachycardia usually affecting patients with serious underlying heart disease.

(2) Ventricular extrasystoles with paroxysms of tachycardia, an essentially milder form affecting those with normal hearts.

(3) In contrast to the terminal forms that are nearly always mortal at short notice, what we then called initial ventricular tachycardia, sometimes due to myocardial infarction, and often of less immediate gravity.

(4) A less familiar group of important ventricular paroxysms developing in those with apparently sound hearts or hearts not greatly injured. We discussed the existence of this group, without expressing an opinion as to the prognosis. Since then, several large series of cases (Campbell, 1947; Herrmann and Hejtmancik, 1948; Armbrust and Levine, 1950; etc.) and many single cases have been reported, all of which have contributed to a clarification of the subject. The approach to ventricular tachycardia, at first electrocardiographic, is becoming more and more clinical and the existence of several distinct types has been confirmed. 
The purpose of this paper is not so much to bring forward new facts, as to propose a classification and an interpretation of the various forms of ventricular tachycardia based primarily on their different modes of evolution. In this connection we shall refer to cases that we have observed which are noteworthy on account of particular features.

\section{Terminal Prefibrillatory Ventricular Tachycardia}

This type was the first to be recognized (Gallavardin, 1920). It is always associated with myocardial damage or exhaustion, and usually indicates that the end is drawing near. The clinical picture, the usual electrical polymorphism or alternance, and the frequent role of digitalis as a factor are too well known to need emphasis. These paroxysms do not seem to belong to any special ætiologic type of cardiopathy but, from a clinical point of view, they merely indicate the pre-terminal decline of an exhausted myocardium. We believe with Mahaim that damage to the conduction system is the predominant factor. Besides their great prognostic value, they are interesting because they are so often heralded by characteristic electrical prodromes (Gallavardin's prefibrillatory ventricular syndrome): these warnings indicate the need for discontinuing digitalis or at least for giving it with the utmost caution since it can easily aggravate the trouble.

\section{Curable and Mild Monomorphic Ventricular Extrasystoles with Paroxysms of TACHYCARDIA}

This type is entirely different from the first and, since Gallavardin's original descriptions, its particular features, its benign course, and its curability have become well established. It is characterized by an almost permanent extrasystolic irregularity interspersed with paroxysms of tachycardia of brief duration; in severe forms these paroxysms tend to become longer and longer until they coalesce into prolonged attacks which are interrupted by sinus beats only at long intervals. This trouble specially affects young subjects with healthy hearts and, as a rule, it is very resistant to therapy, including quinidine.

The paroxysms are strictly monomorphic from an electrical point of view; the frequent isolated extrasystoles have the same contour as the beats that constitute the paroxysms. It is a rare functional disorder which may cause vertigo with alternating pallor and flushing of the face such as is seen in Stokes-Adams syndrome; more rarely faintness occurs at the onset, and still more rarely, episodes of transient heart failure occur when the attacks are unusually prolonged (Gallavardin). Yet the essentially benign character of these paroxysms is proved by their persistence over long periods, for example two of our cases were followed over periods of 35 and 24 years: in both the disorder proved perfectly benign and in both it was completely cured in spite of its initial severity.

Case 1. A woman was regularly observed from 33 to 64 years of age (1920-51) with ventricular extrasystoles and paroxysms of tachycardia: these were intense for the first 20 years, but gradually improved and almost completely disappeared during the last 15 or 20 years.

This case was originally published by Louis Gallavardin; further information was supplied by Froment (1932) and by Léon Gallavardin (1946). The patient was re-examined in 1951 when she was perfectly well and completely free from her trouble.

From 1915 to 1932 the rhythm disorder was very persistent with innumerable ventricular extrasystoles. During bad periods there were prolonged paroxysms of tachycardia lasting 5 to 30 days, with asystolic manifestations; they were of such intensity that the severe ascites wrongly led to a diagnosis of tuberculous peritonitis, and in our absence the patient was submitted to operation.

After 1932 the trouble diminished, the paroxysms became shorter and shorter, not exceeding ten seconds, and much less frequent. Since that time she has been working hard as a midwife in a hospital and in 1946 she only presented infrequent extrasystoles with occasional paroxysms. At present she is in excellent health and leads an active life for a 64-year-old woman.

The cardiovascular examination between attacks showed nothing abnormal; in 1946 her blood pressure was $130 / 80 \mathrm{~mm}$., the size of the heart was normal, and so was the electrocardiogram except for infrequent ventricular extrasystoles similar to the more numerous ones presented before. In 1951, there was no longer any disturbance of rhythm or any sign of heart failure. 
Case 2. A man was under observation from 17 to 41 years of age (1927-51) with ventricular extrasystoles and paroxysms of tachycardia, at first of great intensity, but completely disappearing for the last 20 years.

This case was originally recorded by Gallavardin and Veil (1929), and later by Froment (1932; obs. II) and by Gallavardin (1946; obs. I). When seen again in 1951, he was absolutely normal from a cardiovascular point of view.

From 1927 to 1931 he was extremely uncomfortable with innumerable extrasystolic paroxysms which were badly tolerated. Every paroxysm lasting more than 3 or 4 seconds caused faintness with facial pallor, and once with loss of consciousness. In bad periods, paroxysms were almost continuous to the point that he had to abandon his studies. In better periods there were frequent extrasystoles similar in form to those of the paroxysms.

After 1932, the trouble gradually improved and the patient was able to lead a normal life; he fought in 1939 and spent 30 months as a prisoner of war, with very little trouble. He was re-examined in 1946 and again in 1951, when he was perfectly well and free from extrasystoles. Cardiac examination was normal, the blood pressure was $140 / 80 \mathrm{~mm}$., radioscopy showed that the size of the heart was normal, and the electrocardiogram was also normal.

These two clinical reports testify to the benignity of this rhythm disorder. Though it had been severe in both, the ectopic rhythm disappeared completely and, after many years, they are free from all signs of failure. Therefore, neither the duration nor the repetition of the ventricular paroxysms constitutes an element of gravity. What seems to be important is the general myocardial integrity in young subjects who are capable of tolerating the most frequent paroxysms. It is likely that such rhythm disorders are caused by microscopic myocardial injury, probably of the bundle of His, acting as an épine irritative. The effect of this may gradually lessen on account of its evolution, or of change in the patient's neuro-vegetative condition as he grew older.

\section{Paroxysmal Ventricular Tachycardia due to a Lesion of the Ventricular Septum}

Since the original paper of Robinson and Herrmann (1921) showing the frequency of septal infarction in ventricular tachycardia, this special form has become well known. The work of Levine (1927) alone and with Fulton (1929) and Stevens (1927) contributed to establish its clinical features and therapy. Appearing at or closely following the clinical onset of cardiac infarction it may rarely be the only sign of this and, especially in elderly patients, it is always suggestive. The appearance of ventricular tachycardia on the occasion of a cardiac infarct is a serious danger, with the risk of heart failure and sudden death from ventricular fibrillation. However, thanks to quinidine, which is the fundamental drug in such cases, there may be important remissions even after long and recurrent attacks which seemed to be serious (5 years in a case of Bérard (1940); 11 years in one of Armbrust and Levine). The possibility of recovery is explained by a regression of the infarcted area responsible for the attacks.

Exceptionally, ventricular tachycardia is related to a syphilitic lesion of the septum. Cossio et al. (1937), reported the first example of it; at necropsy treponema were found in the septal gummatous lesions. Coelho and d'Oliveira (1939) published a similar case, also fatal. A patient whom we observed (Froment et. al., 1944) recovered after intensive treatment and has kept free from paroxysms for the last seven years; his heart now appears normal. The following is a brief report of this case.

Case 3. A man, aged 46, apparently in good health, suffered in 1944 six attacks of paroxysmal ventricular tachycardia within a few weeks, the longest lasting 7 days. Bordet-Wassermann, Kahn, and Meinicke reactions were strongly positive. The attacks yielded readily to an intravenous injection of quinidine. From the start of anti-syphilitic treatment the attacks became progressively less frequent and of shorter duration. After 3 months the patient was well, having had only one very short attack; the serologic tests for syphilis were negative. Seen again in 1951, he was in good health and quite free from paroxysms of tachycardia. Clinical, radioscopic and electrocardiographic examinations show no cardiac abnormality now and serologic tests are negative. 
A possible syphilitic origin of ventricular tachycardia, however exceptional, should be in mind, otherwise the advantage of specific treatment may be missed.

\section{Persistent and Prolonged Ventricular Tachycardia Developing in Sound Hearts USUALLY IN YOUNG SUBJECTS}

Besides the disorders of rhythm described, there are others that do not fit into the previous classification. These relate to prolonged ventricular paroxysms without any break, analogous, at least clinically, to the common paroxysms of the supraventricular tachycardia, though their ventricular origin is proved by the electrocardiogram. They are by no means a prefibrillatory type of ventricular tachycardia for they have neither the poor prognosis nor the cardiographic characteristics of it. They do not conform to the extrasystolic form with long runs of extrasystoles as there are neither isolated extrasystoles nor any short runs. On the contrary, paroxysms always have a massive and well-defined aspect. A vascular origin is very unlikely in young subjects who are often involved.

In 1932, we postulated a ventricular form of paroxysmal tachycardia with sharply defined paroxysms, affecting subjects with apparently healthy hearts, and running a benign course. Unquestionably, prolonged paroxysms of ventricular tachycardia do occur in patients with sound hearts, but can we expect the same benign course as occurs in the ordinary case of paroxysmal auricular tachycardia? It is difficult to be sure as the only irrefutable proof of benignity is the test of time. In this connection, we may cite a case which we have followed for a period of 11 years, and we may also cite reports by Bjerkelund (1949), Stein and Driscol (1947), Freunlich (1946), MacMillan and Bellet (1931), Campbell (1942), Clerc et al. (1933), Gaquière and Robin (1947), Peters and Penner (1946), Joly (1927), Donzelot et al. (1945), and Smith (1946).

Case 4. A man was observed from the age of 49 to 60 years (1939-50) during which he had over 400 attacks of ventricular tachycardia, usually lasting several days, and often requiring for an interruption an intravenous injection of quinidine. There was no sign of cardiopathy. In December, 1951, after the electrocardiogram was strictly normal, he was still subject to milder attacks.

D. . . . has been regularly observed by Dr. Bérard of St. Etienne since 1939, since which date he has been seen on several occasions by ourselves. He is apparently in good health except for an old healed lesion of the right lung, probably tuberculous. A benign diabetes mellitus has disappeared without having been treated. This man had led a normal life up to 1939, when at the age of 49 he began to have paroxysms of tachycardia at a rate 300 a minute, starting and ending abruptly. These attacks lasted from a few hours up to several days; the more prolonged ones led to a lipothymic state and forced the patient to rest. The frequency of the attacks varied from time to time; often he had several a month, sometimes several in the same week. These paroxysms were treated by injections of quinidine when they lasted more than two or three days. In 1942, we recognized their ventricular origin and noticed a very distinct dissociation of the jugular pulse.

In 1944, the attacks accurred far more frequently almost every day, and sometimes lasted as long as five days. Quinidine was always effective but it did not prevent the attacks. Five stellate-ganglion blocks gave no result. This state persisted during 1945 and 1946, though with better periods that could not be attributed to therapy.

In 1947 the patient called in a colleague who tried thoracic radiotherapy, an appendicectomy, and lastly a hemithyroidectomy, without success. Soon after the thyroid operation unexplained anasarca developed without cardiac signs and without relation to any prolonged attack; this cleared up within a month and never recurred.

In 1948 and 1949 he was still having frequent attacks. Since June, 1950, they have become shorter, lasting only one hour and less frequent; furthermore, oral quinidine has acted satisfactorily.

Cardiac examination between the attacks was always negative. There was no sign of heart failure apart from the unexplained anasarca following thyroidectomy. When last seen in 1950 there was regular sinus rhythm; radioscopy showed a heart of normal size; blood pressure was $100 / 70 \mathrm{~mm}$. $\mathrm{Hg}$; the cardiogram was normal, the electrical axis of QRS being $+80^{\circ}$. During the attacks, it shows a typical ventricular tachycardia, rate 200 to 210 , with a dissociated auricular rhythm in lead II; there is post-paroxysmal inversion of $T$ waves in leads II and III. 
Comment. This case is a typical example of the ventricular form of Bouveret's disease. The paroxysms start and end suddenly, their frequent repetition rendered the patient an invalid at times and, finally, after 400 attacks during a period of eleven years, the heart remains intact. As the trouble started at the age of 49. a slight vascular lesion cannot be excluded, but such a benign course could not have been forseen when the attacks first occurred.

Case 5. A young man of 21 presented in two years and a half about thirty paroxysms of ventricular tachycardia lasting up to 24 days and always well tolerated. Cardiac examination was negative.

He had always been in good health, and worked as a craftsman without any fatigue, and had played games such as football. In June, 1948, he complained of feeling tired and of right subcostal discomfort, and we found a regular tachycardia at 170, of which the patient was unaware. After many therapeutic failures (intravenous acethycholine, oral quinicardine, and dilvasene) an intravenous injection of quinidine put an end to the attack. Levine's sign had been noticed, with obvious irregularities in the intensity of the first sound. In August, 1948, several slight attacks lasting 2 or 3 days were terminated by oral quinidine.

In September, another attack began and continued for twenty-four days without interruption. The cardiograms showed a typical ventricular tachycardia, rate 174 . The electrical axis was at $+90^{\circ}$ and the dissociated auricular rhythm was well seen in lead II. Variability of the first sound and jugular dissociation were obvious. All treatment, including intravenous quinidine was ineffective until the attack came to an end soon after administration of $1.2 \mathrm{~g}$. of oral quinidine in four hours. During this attack, there was a very remarkable dilatation of the heart that receded within a week and a post-critical diastolic gallop which disappeared a few days later. Finally, we recorded typical post-paroxysmal cardiographic anomalies, namely flattening of $T$ in lead $I$ and deep inversion of $T$ in V4, both of which disappeared within ten days. In the next three months, the patient had many short attacks, which were checked by oral quinidine. At the end of December, three days after an attack, there was slight dilatation of the heart and a normal cardiogram except for a flattened TI.

During 1949 and 1950, the patient had about one attack monthly, usually lasting a few hours, but was able to lead a normal life. Examination of the heart was negative between the attacks, the blood pressure being $12070 \mathrm{~mm}$. and the cardiogram being normal. In November, 1950, he was reported as having only occasional attacks, and as leading an entirely normal life.

Case 6 (Dr. Froment and Trocmé). A 19-year-old man was in good health when, in June, 1947, while bathing, he presented a sudden ventricular paroxysm, rate 232. The attack lasted four days and came to an end after $1.2 \mathrm{~g}$. of quinidine by mouth; shortly before the end of the attack, the rate fell to 192 , and frequency of micturition occurred. The cardiogram showed a typical ventricular tachycardia, though the auricular rhythm was not evident. During the paroxysms, the electrical axis was at $+30^{\circ}$. There were post-paroxysmal changes, namely, flattening of the $T$ wave in lead $I$ and considerable lengthening of the Q-T interval ( 0.56 secs.) which disappeared within ten days. Clinical and radiological examination showed that the heart was normal. In January, 1951, three and a half years later, the patient is reported to be leading a normal life, free from paroxysms.

This form of arrythmia consists of major paroxysms of ventricular tachycardia in subjects with apparently healthy hearts, and follows a favourable course even when of long duration. From the clinical standpoint, this ectopic rhythm resembles the common form of auricular paroxysmal tachycardia, and it may continue a favourable course for ten years or longer.

The age of onset of the paroxysms is variable, but is commonly around 20 years. Men predominate, the sex ratio being ten men to three women. The onset and offset of the paroxysms are well defined, as in ordinary paroxysmal tachycardia and the rate is high (159 to 243), but the duration of the attacks is noticeably longer, an important point of difference. Attacks lasting several days are the rule, and a duration of a week or longer is not uncommon, being observed in four out of ten cases. In paroxysmal atrial tachycardia, especially at the start, the attacks are usually shorter, for in 177 cases only 8 per cent of the attacks lasted longer than 5 days (Gallavardin and Froment, 1930). Finally, the paroxysms are usually well tolerated, rarely provoking faintness or heart failure which, if they occur, are nearly always in the more prolonged attacks.

Electrocardiographic changes are very common after paroxysms of this form of ventricular tachycardia. They have been much studied in recent years, especially by Cossio et al. (1944) who investigated them in 26 cases. Two main types of post-paroxysmal cardiographic change are 
recognized, namely type TI (and TII), and type TIII (and TII). Type TI follows paroxysms in which there is a right electrical axis, and type TIII those with a left electrical axis, this rule applying to about two-thirds of cases. These important and often long-lasting changes in the cardiogram (lasting up to 54 days in a case reported by Smith, 1946) do not correspond to any serious myocardial damage for the lesion could scarcely recur in identical form after successive attacks. In two such cases examined at necropsy by Cossio, no macroscopic lesion was found. Experience shows that the occurrence of these post-paroxysmal electrical changes does not warrant a bad prognosis. Our case observed for 11 years presented gross changes of this type yet there were no serious consequences.

The origin of these ventricular paroxysms still remains a mystery. Our knowledge of cardiac physiology leads us to postulate the existence of an irritable focus in the septum, and probably a histological lesion of the conducting system that does not impair the functioning of the heart, so that the attacks are well tolerated. It is neither the long duration of the attacks nor their ventricular origin that is serious, but the deep septal lesion. In some cases, this lesion may be microscopic and without any effect on the functioning of the heart.

\section{SUMMARY}

From personal observations and from a survey of reported cases, a clinical classification of the different forms of paroxysmal ventricular tachycardia is proposed as follows.

(1) Terminal prefibrillatory ventricular tachycardia (Gallavardin, 1920) usually complicating serious heart disease.

(2) Ventricular extrasystoles with paroxysms of tachycardia, a less serious form usually affecting healthy hearts.

(3) Ventricular paroxysmal tachycardia due to a serious septal lesion, especially septal infarction, and rarely a septal syphilitic lesion.

(4) Major paroxysms of ventricular tachycardia occurring usually in young subjects with apparently healthy hearts. This form resembles clinically the common paroxysmal auricular tachycardia. The clinical course may remain favourable even for ten years or longer. It is suggested that this disorder results from a microscopic lesion which is without effect on the functioning of the heart.

\section{REFERENCES*}

Armbrust, C., and Levine, S. (1950). Circulation I, 28.

Bérard, A. (1940), Arch. Mal. Ceur., 33, 50.

Bjerkelund, Ch. (1949). Acta med. Scand., 133, 139.

Campbell, M. (1942). Brit. Heart J., 4, 49.

(1947). Lancet, 2, 641 and 681.

Cheynel, R. (1950). Thèse de Lyon.

Clerc, A., Lévy, R., and Zadoc-Kahn, B. (1933). Arch. Mal Cour., 26, 249.

Codina Altes, J., and Pijoan de Beristain, C. (1948). Méd. Clinica., 10, 212.

Coelho, E., and d'Oliveira, A. (1939). Arch. Mal Cour., 32, 17.

Cossio, P., Vicoli, D., and Caul, H. (1937). Am. J. med. Sci., 194, 164.

- Vedoya, R., and Berconsky, I. (1944). Rev. argent. Cardiol., 11, 164.

Currie, G. (1942). Brit. Heart J., 4, 149.

Dieuaide, F. R., and Davidson, E. (1921). Arch. intern. Med., 27, 663.

Donzelot, E. (1943). Arch. Mal. Caur., 36, 104.

- Sikorav, H. and Essel (1945). Arch. Mal. Ceeur., 38, 19.

Van Dooren, F., Boyaadjian, N., and Martin, L. (1950). Acta Cardiologica, 5, 77.

Eisaman, J. L. (1945). Amer. Heart J., 30, 401.

Freunlich, J. (1946). Amer. Heart J., 31, 557.

Froment, R. (1932). Thèse de Lyon. Masson et Cie édit., Paris.

-, Blondet, P., and Coblentz, B. (1944). Arch. Mal. Caur., 37, 65.

-, and Gonin, A. (1938). Arch. Mal. Caur., 31, 645.

, and Jourdan, F. (1938). Arch. Mal. Ceur., 31, 792.

Gallavardin, Léon. (1946). Thèse de Lyon. Doin édit. Paris, and J. Méd. Lyon, $27,821$.

* Some references not now in the text have been retained. 
Gallavardin, Louis. (1920). Arch. Mal. Caur., 13, 121.

(1922). Arch Mal. Caur., 15, 298.

(1926). J. Méd. Lyon., 7, 449.

, and Froment, R. (1930). J. Méd. Lyon, 11, 517.

, and Veil, P. (1929). Arch Mal. Cour., 22, 25.

Gallemaerts, E. (1923). Bruxelles Med., 10.

Gaquiere, A., and Robin (1947). Arch. Mal. Cour., 40, 240.

Geiger, A. (1943). Amer. Heart J., 26, 55.

Graybiel, A., and White, P. D. (1934). Amer. Heart J., 10, 345.

Herrmann, G. R., and Hejtmancik, M. (1948). Ann. intern. Med., 28, 989.

Joly, F. (1927). Arch. Mal. Caur., 3, 177.

Levine, S. (1927). Amer. Heart. J., 3, 177.

, and Stevens, W. (1927). Amer. Heart J., 3, 253.

Lian, C., Azerad, Delarue, Facquet, and Cambon (1940). Arch. Mal. Cour., 33, 1-8.

, Welti, J. J., Siguier, F., and Sarrazin, A. (1947). Arch. Mal. Ceeur., 40, 140.

Metzger, H., and Herr, R. (1947). Arch. Mal. Cour., 40, 32.

MacMillan, Th., and Bellet, S. (1931). Amer. Heart J., 7, 70.

Parkinson, J., and Papp, C. (1947). Brit. Heart J., 9, 241.

Peters, M., and Penner, S. L. (1946). Amer. Heart J., 32, 645.

Prinzmetal, M., and Kellogg, F. (1934). Amer. Heart J., 9, 370.

Robinson, G., and Herrmann, G. (1921). Heart, 8, 59.

Routier, D. (1937). Arch. Mal Cour., 30, 224.

, and Puddu, V. (1936). Arch. Mal. Caur., 29, 676.

Smith, L. B. (1946). Amer. Heart J., 32, 257.

Soulié, P. (1938). Arch. Mal. Ceur., 31, 111.

Stein, H., and Driscol, R. E. (1947) Ann. intern. Med., 26, 769.

Ward Lawrence, S. (1946). Amer. Heart J., 31, 645.

Wolferth, C., and MacMillan, T. (1923). Arch. intern. Med., 31, 184. 